\title{
Research of efficiency of lignite chemical modification and steam-gas activation combining for sorbents preparation*
}

\author{
Elena Vorsina ${ }^{1 * *}$, Tatiana Moskalenko ${ }^{1}$, Valery Mikheev ${ }^{1}$ and Mehmet Bilen ${ }^{2}$ \\ ${ }^{1}$ Mining Institute of the North named after N.V. Chersky, SB RAS, Yakutsk, 677018, Russian \\ Federation \\ ${ }^{2}$ Zonguldak Bulent Ecevit University, Turkey
}

\begin{abstract}
The paper presents the results of research for sorbents preparation when combining the processes of chemical modification and steam-gas activation of lignite from the Kharanorsk deposit (Zabaikalsky Krai). The experimental studies were carried out by two ways of activation methods combination: parallel and successive exposure on feedstock. The lignite processed by chemical reagent $(\mathrm{KOH})$ was exposed to steam during the whole period of thermolysis under the parallel action. Under successive exposure, the thermolysis was performed in two stages - first without steam supply, then with steam-gas activation. In the work the optimal parameters of the process of combining the chemical and steam-gas lignite activation methods were determined and the quality of the generated sorbents was studied. The efficiency of combined activation was estimated by comparing the sorption characteristics of the samples with the results obtained during chemical and steam-gas activation as autonomous processes and with the requirements to these characteristics of industrially produced active carbon grades. Combined activation of lignite allowed to increase the value of iodine adsorption activity in comparison with autonomous steam-gas activation by 1.8-2 times, chemical activation - by $2.7-10 \%$. The obtained values of iodine adsorption activity at combination of chemical modification and steam-gas activation exceed the value of 100 $\%(1000 \mathrm{mg} / \mathrm{g})$ that meets the requirements to high quality industrially produced active carbons of SKT-0 grade.

Key words: lignite, alkaline activation, steam-gas activation, carbon sorbents, active carbon, iodine adsorption activity, isothermal time, thermal shock
\end{abstract}

\section{Introduction}

The development of new methods of primary resources advanced processing for remanufacture improvement and development is now one of the most promising trends to ensure economic and social development of the Far East and Baikal region [1]. Mineral

\footnotetext{
* The work was performed under the Fundamental Research Program (Project No 0297-2020-0043)

** Corresponding author: labkiy@mail.ru
} 
resource base development, new processing facilities will undoubtedly lead to progressive development of macro-region accompanied by increasing ecological burden on unique ecosystems. In this connection, the increased demand for quality and accessible sorption materials creates prerequisites for the need to process local raw materials into sorbents with the required set of properties. In this regard, lignite from the Far East and Baikal region deposits becomes an advanced material for sorbents.

The main principles of modern traditional technologies of sorbents production from solid carbon precursors are based on physical or chemical activation processes. Physical (steam-gas) activation consists in thermal oxidation treatment of materials at temperatures of $500-1000^{\circ} \mathrm{C}$ in an inflow of water, $\mathrm{CO}_{2}$ or air vapor; chemical activation - in carboncontaining material impregnation with chemical reagents. These two main methods are aimed at creation of microporous structure and increase of pore surface area per unit of obtained product mass [2-7].

The study of efficiency of combining the chemical modification and steam-gas activation for sorbents preparation was preceded by the study of these activation methods as separate processes. The experimental studies were carried out in three stages:

Stage 1: Chemical activation.

Stage 2. Steam - gas activation.

Stage 3: Combined activation (chemical and steam-gas cycle).

At each stage of the research the optimal process parameters were determined and the sorbents quality was studied. The results have been estimated by comparing the qualitative characteristics of the prepared sorbents with the industrially produced active carbon grades (AC).

Lignite of the Kharanorsk deposit (Zabaikalsky Krai) of B2 grade and 0-2 mm grainsize category was used as carbon-containing material for sorbents, its qualitative characteristics are given in Table 1.

Table 1. Technical analysis and sorption properties of the Kharanorsk deposit lignite.

\begin{tabular}{|c|c|c|c|c|c|}
\hline \multirow{2}{*}{ Grain-size class } & \multicolumn{4}{|c|}{ Technical analysis indicators, \% } & \multirow{2}{*}{$\mathrm{X}, \%$} \\
\cline { 2 - 5 } & $\mathrm{W}^{1}$ & $\mathrm{~W}^{\mathrm{a}}$ & $\mathrm{A}^{\mathrm{d}}$ & $\mathrm{V}^{\text {daf }}$ & \\
\hline $0-2 \mathrm{~mm}$ & 8.2 & 7.6 & 7.9 & 45.5 & 16.9 \\
\hline
\end{tabular}

In the table (hereinafter): $\mathrm{W}^{1}$ - sample laboratory moisture, $\%$; $\mathrm{W}^{\mathrm{a}}$ - analytical moisture content, \%; $\mathrm{A}^{\mathrm{d}}$ - ash on the dry basis, \%; $\mathrm{V}^{\text {daf }}$ - output of volatile substances on dry ash free state, \%; X - iodine adsorption activity, $\%$.

\section{Experiment}

\subsection{Chemical activation (Stage 1)}

The method of chemical activation as a separate process was studied under the impact of various chemical reagents (phosphoric acid, hydrogen peroxide, ammonia, zinc chloride, alkali metal hydroxides, etc.) on lignite. The materials were impregnated with chemical reagents in various ratios, then after the impregnation set time the prepared samples were treated by thermolysis with the subsequent isothermal exposure without air access. The obtained samples were washed with distilled water to neutral medium and dried.

It is established that from the considered chemical reagents the alkali metal hydroxides have the most effective influence on adsorption activity of the Kharanorsk lignite samples. The effectiveness of fossil coals activation by alkali metal hydroxides $(\mathrm{LiOH}, \mathrm{NaOH}$, $\mathrm{KOH}$ ) for obtaining carbon materials with high parameters of porous structure has been confirmed by a number of studies [8-17]. In addition to the porous structure development, 
the alkali provides a high proportion of micropores, a narrow distribution of pores size and significantly reduces the porous material ash content due to the reaction with the mineral components of the starting raw materials. Thus, the obtained total pore volume grows monotonically in $\mathrm{LiOH}<\mathrm{NaOH}<\mathrm{KOH}$ line $[16,17]$.

In the laboratory of complex coal use of Mining Institute of the North (MIN SB RAS) the activation method of the Kharanorsk deposit lignite with potassium hydroxide was developed, the studies on influence of $\mathrm{KOH} /$ lignite ratio, temperature and thermolysis modes on adsorption activity of the obtained samples were carried out. The optimal parameters of chemical (alkaline) activation of the Kharanorsk lignite have been revealed: impregnation of lignite material with potassium hydroxide with the $1 \mathrm{~g} / \mathrm{g}$, ratio, thermolysis in the thermal shock mode at $800^{\circ} \mathrm{C}$ with subsequent $60 \mathrm{~min}$ isothermal time without air access $[18,19]$.

Alkaline activation of the Kharanorsk deposit lignite at optimal parameters allows to obtain carbon materials with high values of iodine adsorption activity $(X=99.9 \%-$ sample 1) corresponding to the level of AC of such marks, as KAD-ground (X no less than $80 \%$ ), UAF (X no less than $70 \%$ ) and high-quality active carbon SKT-0 (X no less than $95 \%$ ), which are used for liquids and solutions clarification and purification, for flotation of nonferrous metal ores, in agricultural production.

However, the method of alkaline activation has the following disadvantages: the need to introduce large amounts of catalyst and problems of its reuse, an additional washing stage $[5]$.

\subsection{Steam-gas activation (Stage 2)}

At present steam-gas activation is the main method of producing active carbons. In comparison with chemical activation this method is technologically more simple and environmentally safe [2, 3].

To carry out experimental studies of steam-gas activation of coal materials for obtaining sorbents in the Laboratory of complex coals use of MIN SB RAS a laboratory unit was assembled, it allows to implement thermal shock and steam-gas activation at temperatures up to $900^{\circ} \mathrm{C}$ [20]. Taking into account the design features of the unit, the method of preparing sorbents from the Kharanorsk deposit lignite was developed and the following optimal parameters of steam-gas activation were revealed: activation without carbonization stage, steam-gas reagent consumption - $250-300 \mathrm{ml} /$ hour, thermolysis at $800^{\circ} \mathrm{C}$, time of steam-gas activation exposure at isothermal holding $-60 \mathrm{~min}$.

At optimum mode parameters of sorbent generation method by steam - gas activation of coal raw materials, the samples, which by the indicator of iodine adsorption activity are attributed to qualitative active carbons, were obtained. In activation by water vapor the iodine adsorption activity was $54.9 \%$ (sample 2), water vapor and $\mathrm{CO}_{2}-56,9 \%$ (sample 3 ). The obtained values of iodine adsorption activity are comparable to the requirements for this value of industrially produced AC of DAK (X > $30 \%)$ and BAU-Au (X > $50 \%)$ grades.

\subsection{Combined activation (Stage 3)}

In this case, the combined activation means a combination of chemical (alkaline) and steam-gas activation, using $\mathrm{KOH}$ and water vapor as activators. Combination of chemical and steam-gas activation processes was carried out by two ways of combining their effect on raw materials: parallel and successive. In case of parallel action, the material treated with chemical reagent is exposed to steam during the whole period of thermolysis. Under 
successive exposure, the chemically treated material is thermolysed in two stages - first without steam supply, then with steam-gas activation.

The revealed optimum parameters of chemical (stage 1) and steam-gas activation (stage 2) as separate processes became the basis for experimental research of combined activation (stage 3) of the Kharanorsk deposit lignite.

Qualitative indicators and iodine adsorption activity of sorbent samples prepared by combined activation of lignite are given in Table 2 .

Table 2. The main results of experiments for sorbents preparation by lignite combined activation.

\begin{tabular}{|c|c|c|c|c|c|c|}
\hline \multirow{2}{*}{ Combined activation } & \multirow{2}{*}{$t_{x}$} & \multirow{2}{*}{$t_{\Pi}$} & \multicolumn{3}{|c|}{ Technical analysis, $\%$} & \multirow{2}{*}{$\mathrm{X}, \%$} \\
\hline & & & $\mathrm{W}^{\mathrm{a}}$ & $\mathrm{A}^{\mathrm{d}}$ & $\mathrm{V}^{\text {daf }}$ & \\
\hline \multirow{2}{*}{ Parallel } & \multicolumn{2}{|c|}{60} & 30.8 & 17.3 & 13.7 & 102.6 \\
\hline & \multicolumn{2}{|c|}{30} & 2.4 & 3.5 & 6.2 & 99.8 \\
\hline \multirow{4}{*}{ Successive } & 30 & 30 & 25.4 & 6.6 & 7.7 & 109.9 \\
\hline & 30 & 60 & 28.0 & 10.0 & 9.9 & 108.9 \\
\hline & 60 & 30 & 26.4 & 11.8 & 9.7 & 103.4 \\
\hline & 60 & 60 & 27.4 & 12.3 & 10.0 & 103.6 \\
\hline
\end{tabular}

In table: $t_{x}, t_{n}-$ time of chemical and steam-gas activation, respectively, min.

\section{Results and discussion}

The analysis of the results of combination of chemical modification and steam-gas activation (stage 3 ) showed that the highest iodine adsorption activity was obtained:

- in the process of parallel chemical and steam-gas activation on the material during 60 $\min (\mathrm{X}=102.6 \%$ - sample 4$)$;

- in the process of successive exposure of chemical and steam-gas activation on the material during $30 \mathrm{~min}$ at each stage $(X=109.9 \%$ - sample 5). The value of iodine adsorption activity under successive exposure to chemical and steam-gas activation with 60 min total duration was by $7 \%$ higher than under parallel exposure. The increase of material processing stages duration under successive exposure did not lead to increase of iodine adsorption activity of the samples.

Thus, the following optimal parameters of the combination of chemical and steam-gas activation of lignite from the Kharanorsk deposit were revealed: processing of materials with potassium hydroxide with $1 \mathrm{~g} / \mathrm{g}$ ratio, a thermal shock at $800^{\circ} \mathrm{C}$ and $60 \mathrm{~min}$ isothermal time, steam-gas reagent consumption of $250-300 \mathrm{ml} /$ hour. The combined activation of succesive exposure is recommended.

The value of iodine adsorption activity of sorbents obtained at optimal parameters of the steam-gas and chemical activation combination exceeds the value of $100 \%(1000 \mathrm{mg} / \mathrm{g})$ (samples 4 and 5), which meets the requirements for high quality industrially produced active carbons of SKT-0 grade (X at least $95 \%$ ).

The results of the experiments at 1-3 stages with optimal activation process parameters are summarized in Table 3. 
Table 3. Experiment results for 1-3 stages at optimal activation process parameters.

\begin{tabular}{|c|c|c|c|c|c|}
\hline \multirow{2}{*}{ 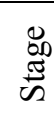 } & \multirow[t]{2}{*}{ Activation } & \multicolumn{3}{|c|}{$\begin{array}{l}\text { Technical analysis } \\
\text { indicators, } \%\end{array}$} & \multirow[t]{2}{*}{$\mathrm{X}, \%$} \\
\hline & & $\mathrm{W}^{\mathrm{a}}$ & $\mathrm{A}^{\mathrm{d}}$ & $\mathrm{V}^{\text {daf }}$ & \\
\hline \multirow{2}{*}{1} & Chemical: & & & & \\
\hline & sample 1 & 20.9 & 11.4 & 14.4 & 99.9 \\
\hline \multirow{3}{*}{2} & Steam-gas: & & & & \\
\hline & - vapour (sample 2) & 12.0 & 20.5 & 12.9 & 54.9 \\
\hline & - vapour and $\mathrm{CO}_{2}$ (sample 3$)$ & 8.9 & 17.5 & 6.2 & 56.9 \\
\hline \multirow{3}{*}{3} & Combined: & & & & \\
\hline & - parallel exposure (sample 4) & 30.8 & 17.3 & 13.7 & 102.6 \\
\hline & - successive exposure (sample 5) & 25.4 & 6.6 & 7.7 & 109.9 \\
\hline
\end{tabular}

According to Table 3, it can be seen that the combined activation made it possible to increase the value of iodine adsorption activity by $1.8-2$ times compared to autonomous steam-gas activation, and chemical activation - by $2.7-10 \%$.

Comparison of iodine adsorption activity of samples from 1-3 stages of the research with the requirements for this indicator for commercially available AC grades is shown in Fig. 1.

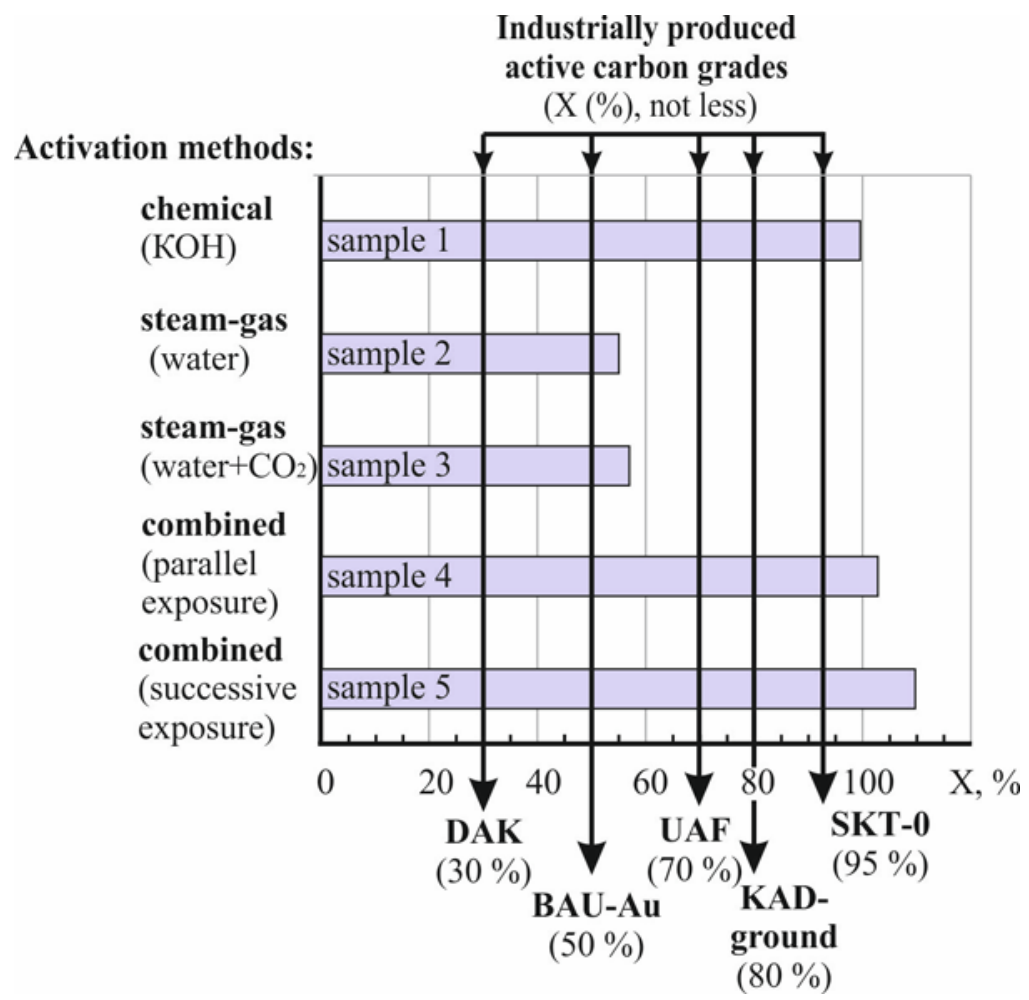

Fig.1. Comparison of iodine adsorption activity of samples obtained at chemical, steam - gas and combined activation with the required quality of active carbons of industrially produced grades. 


\section{Conclusions}

The methodology was developed, the experimental studies were carried out and optimal parameters of sorbent production process were determined using combination of chemical modification and steam-gas activation of lignite from the Kharanorsk deposit.

Combination of chemical and steam-gas activation allows to increase iodine adsorption activity of the obtained samples by up to 2 times in comparison with autonomous steam-gas activation. But it should be noted that the combined activation will be characterized by all disadvantages of the chemical method of coal material activation (necessity to use large amounts of the catalyst; its reuse problems; additional washing stage, etc.), and, consequently, higher production cost and significantly increased environmental impact than in the case of a steam-gas activation method.

Addition of the chemical modification of the Kharanorsk lignite with its steam-gas activation made it possible to increase iodine adsorption activity by $2.7-10 \%$ as compared to chemical activation only.

Treatment of lignite with potassium hydroxide in $1 \mathrm{~g} / \mathrm{g}$ ratio before thermal impact at $800^{\circ} \mathrm{C}$ in thermal shock mode, isothermal exposure during 60 minutes and steam-gas reagent supply with consumption of 250-300 ml/hour at combined activation of successive and parallel exposure allowed to obtain sorbents with iodine adsorption activity value over $100 \%(1000 \mathrm{mg} / \mathrm{g})$, which meets the requirements for high quality industrially produced active carbons of SKT-0 grade (X at least $95 \%$ ).

\section{References}

1. A. Yu. Cheban, G. V. Sekisov, N. P. Khrunina, A. A. Sobolev, S. M. Ugai, Systems. Methods.Technologies, 3(27), 156-161 (2015)

2. V. M. Mukhin, V. N. Klushin Production and use of carbon adsorbents (D. K. Mendeleev Russian University of Chemical Technology, Moscow) (2012)

3. N. V. Keltsev The basics of adsorption technology (Chemistry, Moscow) (1984)

4. J. B. Jia, H. H. Du, G. X. Huang, Q. R. Liu, B. L. Xing, C. X. Zhang, H. Y. Guo, J. N. Pan, Xiandai Huagong. Modern Chemical Industry, 38(6), 24-27 (2018)

5. V. B. Fenelonov, Introduction to physical chemistry of supramolecular structure of adsorbents and catalysts formation, (SB RAS, Novosibirsk) (2002)

6. H. Marsh, F. Rodriguez-Reinoso, Activated Carbon (Elsevier Ltd.) (2006)

7. M. A. Perederiy, Chemistry of solid fuels, 1, 35-44 (2000)

8. A. A. Kurilkin, V. M. Mukhin, S. G. Kireev, L. A. Kargaltseva. Sorption and chromatographic processes 10 (4), 515-521 (2010)

9. M. G. Beletskaya, N. I. Bogdanovich Chemistry of plant raw materials, 3, 77-82 (2013)

10. T. G. Shendrik, Yu.V. Tamarkina,T. V. Khabarova, Chemistry of solid fuels, 5, 51-55 (2009)

11. T. S. Manina, N. I. Fedorova, S. A. Semenova, Z. R. Ismagilov, Coke and chemistry, 5, 25-28 (2013)

12. V. A. Kucherenko, T. G. Shendrik, Yu. V. Tamarkina, R. D. Mysyk, Carbon, 48(15), 45-56 (2010)

13. A. P. Kozlov, I. Yu. Zykov, Yu. N. Dudnikova, V. E. Tsvetkov, N. I. Fedorova, Z. R. Ismagilov, Bulletin of KuzSTU, 3(127), 93-100 (2018)

14. M. A. Lillo-Ródenas, D. Cazorla-Amorós, A. Linares-Solano, Carbon, 41, 267-275 (2003)

15. N. V. Chesnokov N. M., Mikova, I. P. Ivanov, B. N. Kuznetsov, Jour. of Sib. Fed. Univ., Chemistry 7 (1), 42-53 (2014) 
16. Yu. V. Tamarkina, N. N. Tsyba, V. A. Kucherenko, T. G. Shendrik, Issues of Chemistry and Chemical Technology, 3, 132-137 (2013)

17. Yu. V. Tamarkina, T. G. Shendrik, V. A. Kucherenko, T. V. Khabarova, Jour. of Sib. Fed. Univ., Chemistry. 5(1), 24-36 (2012)

18. E. V. Vorsina, T. V. Moskalenko, V. A. Mikheev, Geomechanical and geotechnological problems of the North subsoil development: MIAB, 11(24), 146-154 (2017)

19. E. V. Vorsina, T. V. Moskalenko, V. A. Mikheev, International science and technology conference "Earth Science", IOP Conf. Series: Earth and Environmental Science, 459(4), 052056, (2020). https://doi.org/10.1088/1755-1315/459/5/052056

20. E. V. Vorsina, T. V. Moskalenko, V. A. Mikheev, MIAB, 11, 152-159 (2019) 